\title{
Temperature, plant species and residence time effects on nitrogen removal in model treatment wetlands
}

\author{
Authors: Chris R. Allen, Otto R. Stein, P. B. Hook, \\ Mark D. Burr, Albert E. Parker, \& E. C. Hafla
}

NOTICE: This is a postprint of an article that originally appeared in Water Science \& Technology on December 2013. DOI: http://dx.doi.org/10.2166/wst.2013.482.

Allen CR, Stein, OR, Hook PB, Burr MD, Parker AE, Hafla EC, "Temperature, plant species and residence time effects on nitrogen removal in model treatment wetlands," Water Science \& Technology 2013 68:11, 2337-2343. 


\title{
Temperature, plant species and residence time effects on nitrogen removal in model treatment wetlands
}

\author{
Chris R. Allen, Otto R. Stein, P. B. Hook, Mark D. Burr, Albert E. Parker and E. C.
} Hafla

\begin{abstract}
Total nitrogen (TN) removal in treatment wetlands (TWs) is challenging due to nitrogen cycle complexity and the variation of influent nitrogen species. Plant species, season, temperature and hydraulic loading most likely influence root zone oxygenation and appurtenant nitrogen removal, especially for ammonium-rich wastewater. Nitrogen data were collected from two experiments utilizing batch-loaded (3-, 6-, 9- and 20-day residence times), sub-surface TWs monitored for at least one year during which temperature was varied between 4 and $24{ }^{W_{C}}$. Synthetic wastewater containing $17 \mathrm{mg} / \mathrm{l} \mathrm{N}$ as NH4 and $27 \mathrm{mg} / \mathrm{l}$ amino-N, $450 \mathrm{mg} / \mathrm{l}$ chemical oxygen demand (COD), and $13 \mathrm{mg} / 1 \mathrm{SO} 4-\mathrm{S}$ was applied to four replicates of Carex utriculata, Schoenoplectus acutus and Typha latifolia and unplanted controls. Plant presence and species had a greater effect on TN removal than temperature or residence time. Planted columns achieved approximately twice the nitrogen removal of unplanted controls (40-95\% versus 20-50\% removal) regardless of season and temperature. TWs planted with Carex outperformed both Typha and Schoenoplectus and demonstrated less temperature dependency. TN removal with Carex was excellent at all temperatures and residence times;

Schoenoplectus and Typha TN removal improved at longer residence times. Reductions in TN were not accompanied by increases in $\mathrm{NO}_{3}$, which was consistently below $1 \mathrm{mg} / \mathrm{l} \mathrm{N}$.
\end{abstract}

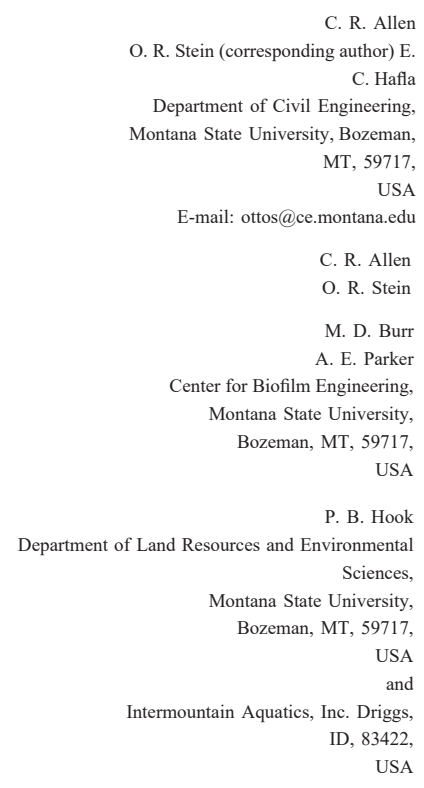

Key words | ammonium, COD, loading rate, season, sulfate

\section{INTRODUCTION}

Nutrient removal in treatment wetlands (TWs) occurs through a complex series of biogeochemical mechanisms, the rate of which has been shown to be influenced by temp-erature, plant species, system design, and loading characteristics (Vymazal 7200; Kadlec \& Wallace 9 20). Total nitrogen (TN) removal is important to the success of many TWs designed for wastewater treatment. Nitrogen removal in wetland systems can occur through both abiotic and biotic pathways including the loss of nitrogen through ammonia volatilization, sorption, accumulation into recalci-trant particulate matter, plant uptake, and various microbially mediated processes (Vymazal 7200). With a few notable exceptions (e.g. Huett et al. 5200; Salvato \& Borin20Io) the metabolism of nitrogen compounds by microbes in the rhizosphere has been shown to account for the majority of total nitrogen (TN) removal. In most instances sequential nitrification and denitrification processes are thought to rep-resent the primary removal pathway (Faulwetter et al. goo; Kadlec \& Wallace goo; Langergraber et al. goo); however, anammox and other ammonium oxidation pathways have been found in TW systems and may play an important role in nitrogen removal depending on system design and influent water conditions (Dong \& Sun 7200; Paredes et al. 7200a, b; Vymazal 7200; Erler 800; Wallace \& Austin 800).

The presence of plants consistently improves TW per-formance (Brisson \& Chazarenc goo), and stimulation of rhizosphere microbial processes is most likely responsible for this. Root zone aeration plays a large role in TW efficacy when systems are loaded with large quantities of organic carbon (typically measured as biochemical oxygen demand (BOD) or chemical oxygen demand (COD)) and reduced nitrogen. In subsurface-flow TWs, physical means used to increase substrate aeration include exposing the wetland media to air through forced aeration, actively varying the water level, and in vertical flow wetlands, pulse loading the treatment bed (McBride \& Tanner 2000; Behrends et al.200I; Brix \& Arias 5200; Vymazal 7200 ,5200; Kadlec \& Wallace 90 2; Langergraber et al. 200920Io). Plants also 
contribute to subsurface aeration by transporting oxygen into the rhizosphere, although plant-mediated oxygen transfer rates are difficult to measure and estimates vary widely (Bezbaruah \& Zhang 2005; Mainiero \& Kazda 2005; Dong et al. 20II). In addition to oxygen, plants actively and passively release a variety of substances that enhance microbial abundance, diversity, and activity around roots including carbon compounds, acids, vitamins and enzymes (Bertin et al. 2003; Cardon 2007; Faulwetter et al. 2009). The amount of oxygen and exudates beneficial to microorganisms in the rhizosphere has been found to vary by plant species (Laskov et al. 2006), and species selection can significantly affect the efficacy of a TW system (Taylor et al. 20II).

Oxygen, whether released by plants or otherwise introduced into the subsurface, acts as a high-energy electron acceptor for both heterotrophic and autotrophic bacteria that compete to oxidize either carbon compounds or ammonium. In planted subsurface-flow wetlands where the water level is not varied, plant roots represent the primary input for oxygen into the subsurface. Redox gradients vary radially around the root (Bezbaruah \& Zhang 2004) and longitudinally along the root (Faulwetter et al. 2012). Microbial biomass and diversity most likely vary in response to these redox gradients, which provide a multitude of niches enabling the aerobic oxidation of carbon compounds, nitrification, and anoxic processes such as denitrification, in close proximity (Bezbaruah \& Zhang 2004; Faulwetter et al. 2012).

In TWs designed to be loaded with raw or primary-treated wastewater containing significant quantities of COD and ammonium, root zone aeration capacity may dictate the treatment efficacy of the system. Oxygenation can be assumed to be the rate-limiting factor affecting COD removal and the initial nitrification process required for denitrification and anammox processes. Past research by our group has focused on relating contaminant removal to plant oxygen input rates across seasons (Stein \& Hook 2005; Stein et al. 2007; Schultz et al. 2008; Taylor et al. 20II). COD removal efficacy has been correlated to temperature, loading-rate and plant species in batch fed subsurface TW microcosms. Relative levels of root zone oxygenation were inferred by comparing COD removal rates, sulfate reduction, and bulk fluid oxidation reduction potential (ORP) measurements. These experiments suggest that plants increase the oxygenation potential of wetland systems and that plant effects are greatest in the winter months and offset reductions in COD removal efficiency that would otherwise result from temperature-induced decreases in reaction rates. To gain a better perspective on how the interrelated mechanisms at work in the rhizosphere might influence nitrogen removal in TWs, we reinvestigated unpublished data from these experiments.

\section{$\overline{\text { METHODS }}$}

The goal of the current analysis was to utilize existing nitrogen data from two long-term controlled-temperature greenhouse experiments (Allen et al. 2002; Schultz et al. 2008) to further elucidate the seasonal effects of specific plant species. The first experiment investigated COD removal over 20-day batch cycles, while the second used a similar experimental design, an identical synthetic wastewater recipe, and 3-, 6-, and 9-day batch cycles to look at the effects of an increased loading rate on COD removal. The two experiments used slightly different annual temperature cycles, but both included periods with temperatures of $4,8,16$, and $24^{\circ} \mathrm{C}$. The data from these temperatures, which comprise approximately 1000 sample-collection events for $\mathrm{COD}, \mathrm{NH}_{4}^{+}$, and sulfate, are included in the current analysis.

Experiments utilized subsurface-flow wetland microcosms (columns) constructed from polyvinyl chloride pipe $(60 \mathrm{~cm}$ in height $\times 20 \mathrm{~cm}$ in diameter) and filled to a depth of $50 \mathrm{~cm}$ with washed pea-gravel $0.3-1.3 \mathrm{~cm}$ in diameter. The same locally-sourced alluvial gravel was used in both experiments. The gravel was derived from noncalcareous rock of igneous and metamorphic origin consisting of approximately $80 \%$ quartz, 10\% aluminum silicates and $10 \%$ mica. The mica and aluminum silicates in the gravel result in a high sorption capacity with a cation exchange capacity estimated to be approximately $190 \mathrm{mEq}$ per $\mathrm{kg}$ of gravel. Porosity decreased slightly over the course of the experiments and overall replicates and times ranged from 32 to $25 \%$.

Experiments were conducted at Montana State University in Bozeman, Montana $\left(46^{\circ} \mathrm{N}, 111^{\circ} \mathrm{W} ; 1,490 \mathrm{~m}\right.$ elev.) from April 1997 to July 1999 (20-day batches) and February 2006 to August 2007 (other batch lengths). Greenhouse temperatures were cycled annually from 4 to 24 to $4{ }^{\circ} \mathrm{C}$ in conjunction with natural daily light cycles to mimic the seasons and induce annual plant growth and senescence patterns. Four replicates of three locally collected plant species, Carex utriculata, Schoenoplectus acutus, and Typha latifolia were compared to replicate unplanted control columns. All treatments were allowed to establish in the columns for at least 8 months prior to data collection. 
Although batch length varied between the experiments, the influent solution recipes were identical, with concentrations averaging $450 \mathrm{mg} \mathrm{L}^{-1} \mathrm{COD}, 44 \mathrm{mg} \mathrm{L}^{-1}$ nitrogen, $8 \mathrm{mg} \mathrm{L}^{-1}$ $\mathrm{PO}_{4}-\mathrm{P}$, and $14 \mathrm{mg} \mathrm{L}^{-1} \mathrm{SO}_{4}-\mathrm{S}$. The nitrogen was introduced into the columns in two forms: $27 \mathrm{mg} \mathrm{L}^{-1}$ as amino-N from peptone and $17 \mathrm{mg} \mathrm{L}^{-1}$ as $\mathrm{NH}_{4}-\mathrm{N}$. In a loading cycle (batch), the columns were gravity drained and fed fresh synthetic wastewater from the top of the column until the water level was just at the surface. Evaporative losses were automatically replaced with tap water, making concentrationbased and mass-based removal identical. Samples were collected from a vertically oriented sampling tube terminating in the geometric center of the column at days 0.04 (20 min.), 1, 3, 6, 9 and 20, as truncated by batch length. Further details for each experiment can be found in the previous publications (Allen et al. 2002; Schultz et al. 2008).

Ammonium and COD were measured in filtered samples using $\mathrm{HACH}$ colorimetric methods 10031 and 8000 , respectively. The anions nitrite, nitrate, sulfate, and phosphate were measured from the same samples using ion chromatography. In both experiments nitrate and nitrite were continually found to be below the detection limit $\left(<1 \mathrm{mg} \mathrm{N} \mathrm{L}^{-1}\right)$. Additionally, TN was measured using $\mathrm{HACH}$ method 10072 at 4 and $24{ }^{\circ} \mathrm{C}$ in the first experiment and at $8{ }^{\circ} \mathrm{C}$ in the second. A previous experiment (Riley et al. 2005) using the same experimental system, but with $\mathrm{NH}_{4}^{+}-\mathrm{N}$ as the sole source of nitrogen, determined that differences in TN between filtered and unfiltered samples were low (typically about $2 \mathrm{mg} \mathrm{L}^{-1}$ ) with no discernible pattern across treatments and sample days, indicating that organic and particulate-bound $\mathrm{N}$ concentration are insignificant in these artificial wastewater experiments. However, ammonium values cannot be directly used to indicate $\mathrm{TN}$ removal because the concentration of aqueous $\mathrm{NH}_{4}^{+}$is related to the sorption capacity of the gravel matrix, the biotic removal rate of $\mathrm{TN}$, and the hydrolysis of the amino- $\mathrm{N}$ to $\mathrm{NH}_{4}^{+}$(Riley et al. 2005). In order to compare nitrogen removal among the various treatments, we estimated $\mathrm{TN}$ from $\mathrm{NH}_{4}^{+}$using the statistical approach described below, based on data from batches for which both $\mathrm{TN}$ and $\mathrm{NH}_{4}^{+}$were measured.

The statistical approach was based on the assumption that $\mathrm{TN}$ and $\mathrm{NH}_{4}^{+}$are related through hydrolysis of the amino- $\mathrm{N}$ to $\mathrm{NH}_{4}^{+}$and that this conversion follows first order dynamics. The observed difference between $\mathrm{TN}$ and $\mathrm{NH}_{4}^{+}$concentrations appeared to follow a first order exponential decay with time corroborating this assumption (Figure 1). Initial differences between $\mathrm{TN}$ and $\mathrm{NH}_{4}^{+}\left(\sim 27 \mathrm{mg} \mathrm{N} \mathrm{L}^{-1}\right)$ decreased rapidly and were $<5 \mathrm{mg} \mathrm{N} \mathrm{L}^{-1}$ in $75 \%$ of samples on day 3 and $100 \%$ of samples by day 9 , regardless of season, plant species or loading rate. Based on this pattern, a non-linear, mixedeffects regression model was fitted to the measured differences between $\mathrm{TN}$ and $\mathrm{NH}_{4}^{+}$using the Linear and Nonlinear Mixed Effects Models package for R build 2.15.1 (Pinheiro et al. and the R Core Team 20I2) and assuming exponential conversion of $\mathrm{TN}$ to $\mathrm{NH}_{4}^{+}$. In the model, plant treatment was used as a fixed effect, resulting in slightly different regression constants for each plant species. Differences between measured and predicted $\mathrm{TN}$ values decreased with time, with the largest errors at 0.04 day and 1 day after filling. By day 3, the modelestimated TN values were within $5 \mathrm{mg} \mathrm{N} \mathrm{L}^{-1}$ of the measured value for $90 \%$ of samples with a median absolute and relative errors of less than $1.5 \mathrm{mg} \mathrm{L}^{-1}$ and 14\%, respectively. From day 6 onward, the model estimated TN was within $5 \mathrm{mg} \mathrm{N} \mathrm{L}^{-1}$ of the measured value for $100 \%$ of the samples with a median absolute error of approximately $1 \mathrm{mg} \mathrm{N} \mathrm{L}^{-1}$. Upon model calibration using samples with measured $\mathrm{TN}$ and

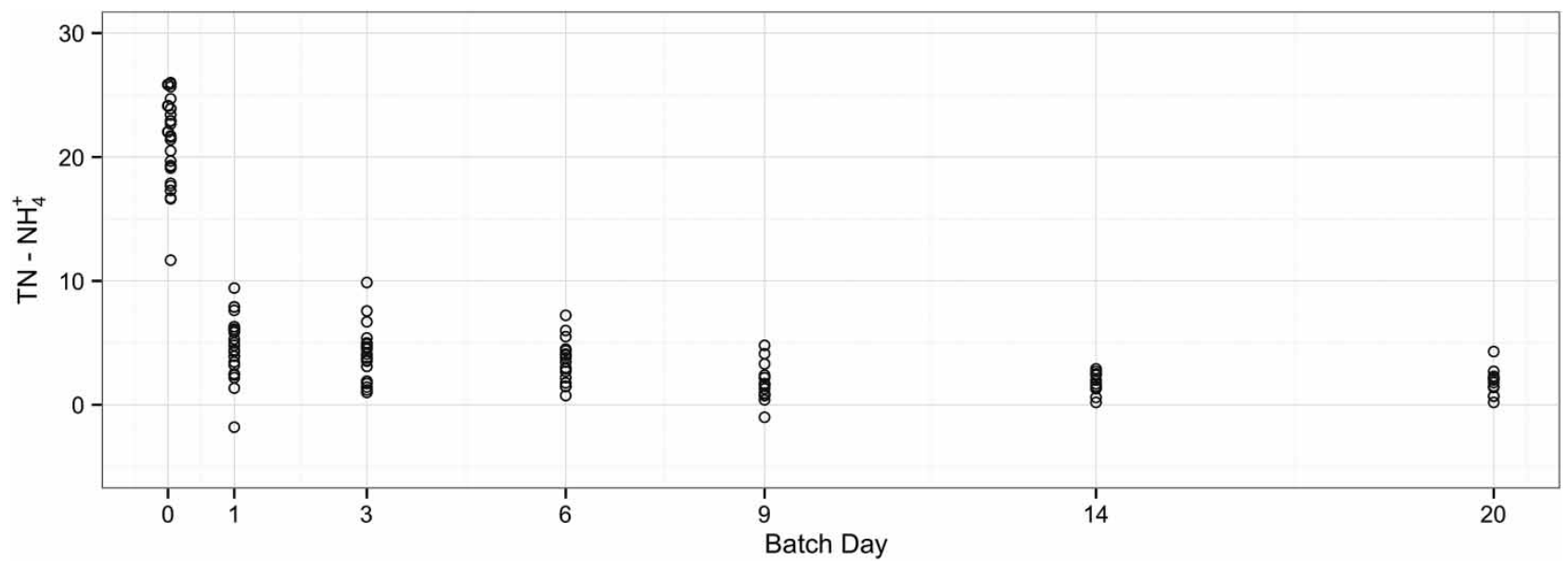

Figure 1 | Differences between measured TN and $\mathrm{NH}_{4}^{+}$values illustrating the first order hydrolysis of the amino- $\mathrm{N}$ to $\mathrm{NH}_{4}^{+}$. 
$\mathrm{NH}_{4}^{+}$, TN for all samples was estimated by adding the predicted difference for a specific species and time to the measured $\mathrm{NH}_{4}^{+}$concentrations. Initial wastewater strength varied within a few percentage points between batches. This variation was quantified for routinely analyzed constituents but usually not for TN. Therefore, the initial concentration of $\mathrm{TN}$ for each batch was estimated by assuming that it differed from the target value of $44 \mathrm{mg} \mathrm{N} \mathrm{L}^{-1}$ by the same proportion that all other constituents differed from their target concentrations for that batch.

\section{RESULTS AND DISCUSSION}

Nitrogen, COD, and sulfate removal values were compared on multiple days within batches across an annual cycle of temperatures. Direct comparisons between the two experiments by season are complicated by the fact that observations started and ended in winter in one experiment and started and ended in summer in the other. However, in both experiments, the data followed seasonal trends that appeared to be correlated more strongly with temperature than plant growth and senescence patterns (e.g. spring and fall). Additionally, results for intermediate temperatures during fall and spring were similar. Therefore, we have combined the data collected at the same temperature, regardless of season. Continuing from past analyses, we address two major questions: to what extent do plant species and temperature influence removal rates, and how does loading rate affect the results?

Previously reported results from both experiments demonstrated that the effects of temperature and plant species on COD and sulfate concentrations were pronounced and consistent by day 6 for all batch lengths of 6 days or longer. Model-estimated TN values also had minimal variance by day 6. Therefore, we focused first on differences in COD, sulfate and TN removal at day 6 as a function of plant species and temperature using aggregated data for 9-day and 20-day batches (Figure 2). The number of data points per plant species varied between 12 and 16, depending on the temperature. Wide ranges of COD and sulfate removal values were measured at most temperature steps; the range of variation generally increased at lower temperatures. Despite the relatively large variance observed in the aggregated data, differences in COD and sulfate between temperatures and species were typically statistically significant within each experiment (Stein \& Hook 2005; Schultz et al. 2008) and similar across experiments. Carex and Schoenoplectus

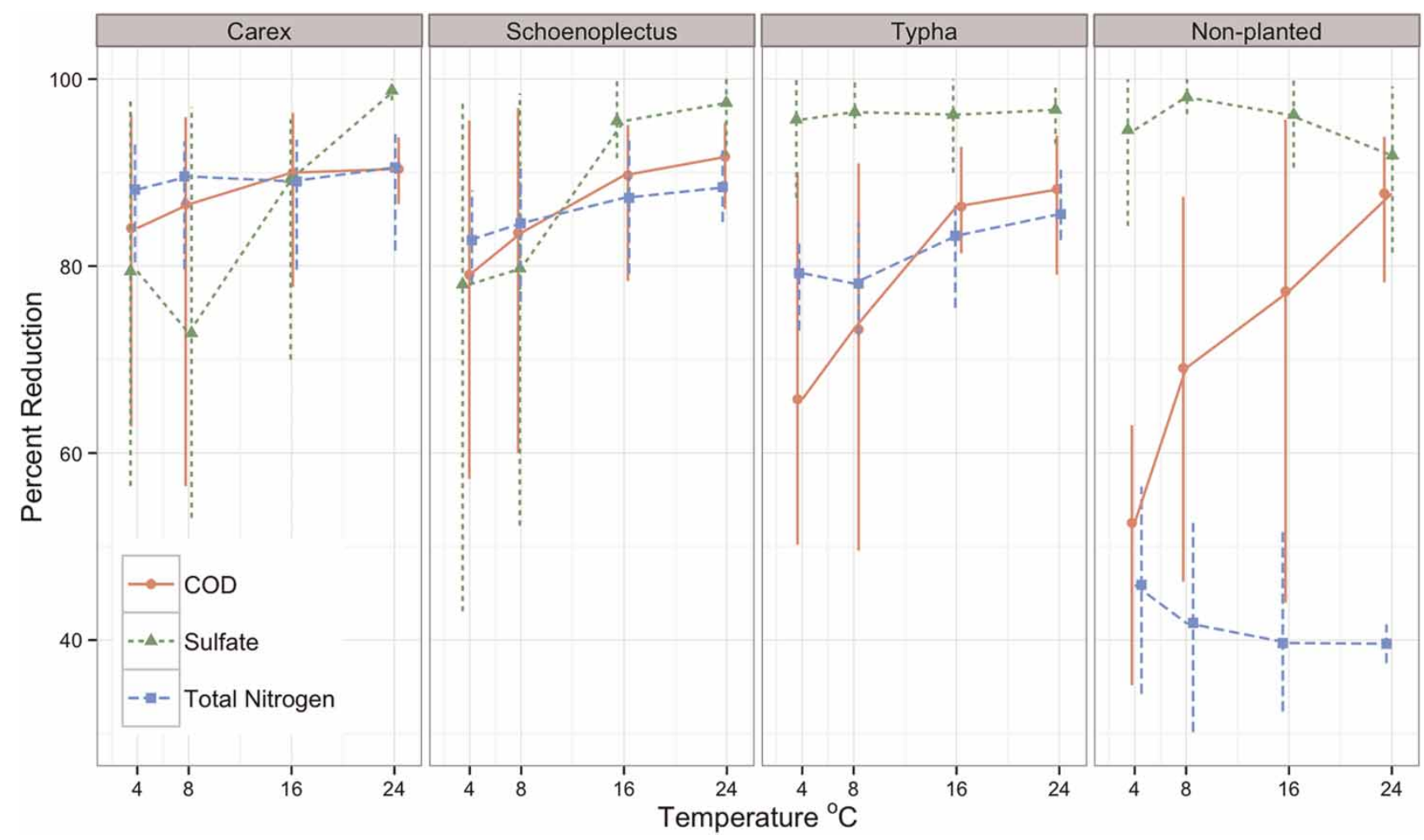

Figure 2 | Percent removal values for TN, COD, and sulfate at day 6 of aggregated 9- and 20-day batch lengths. Points represent mean values; vertical bars represent the maximum and minimum values. 
demonstrated significantly greater sulfate removal at warmer temperatures, but sulfate removal did not vary with temperature in Typha columns and unplanted controls. In contrast, Typha and unplanted treatments demonstrated significantly greater COD removal at warmer temperatures, while COD removal in Carex and Schoenoplectus was insensitive to temperature. Sulfate removal was negatively correlated with ORP, suggesting that treatment effects were related to root zone aeration. Specifically, the lack of temperature dependence for COD removal in columns with Carex and Schoenoplectus appeared to be related to increased oxygenation of the rhizosphere in winter.

Interestingly, nitrogen removal varied less within treatments and temperature steps than COD and sulfate removal and was also less sensitive to temperature. The presence of plants increased nitrogen removal dramatically, often doubling rates regardless of temperature. When plants were present, species affected $\mathrm{TN}$ removal more than temperature. Carex columns removed the most TN and Typha columns removed the least at all temperatures. All planted columns displayed weak increases in TN removal with increased temperature, but better performing species displayed the weakest temperature effect.
Although some studies have shown that plant uptake can be a significant nitrogen removal mechanism in immature systems (Salvato \& Borin 2010; Borin \& Salvato 2012) at loading rates similar to ours, differences between treatments in our study using microcosms that had at least one growing season to mature prior to data collection are most likely due to differences in microbial metabolism (Paredes et al. 2007a, b; Vymazal 2007; Langergraber et al. 2009). Taken together with the results for COD, sulfate, and ORP, these data suggest that aerobic nitrification is the factor limiting TN removal and that root zone aeration is at least partly responsible for the effects that plants have on TN removal and its response to temperature. We hypothesize that in unplanted gravel, TN removal decreases as temperature increases because heterotrophic bacteria outcompete autotrophic nitrifiers for the very limited oxygen in the system; heterotrophic reaction rates may be sufficiently retarded at lower temperatures to increase oxygen availability for the nitrifying bacteria. While nitrifying bacteria are most likely also inhibited by lower temperatures, the availability of some oxygen may allow for an increase in nitrifier activity relative to heterotrophic activity. However, the overall lack of available oxygen inhibits both heterotrophic and autotrophic aerobes at all temperatures.

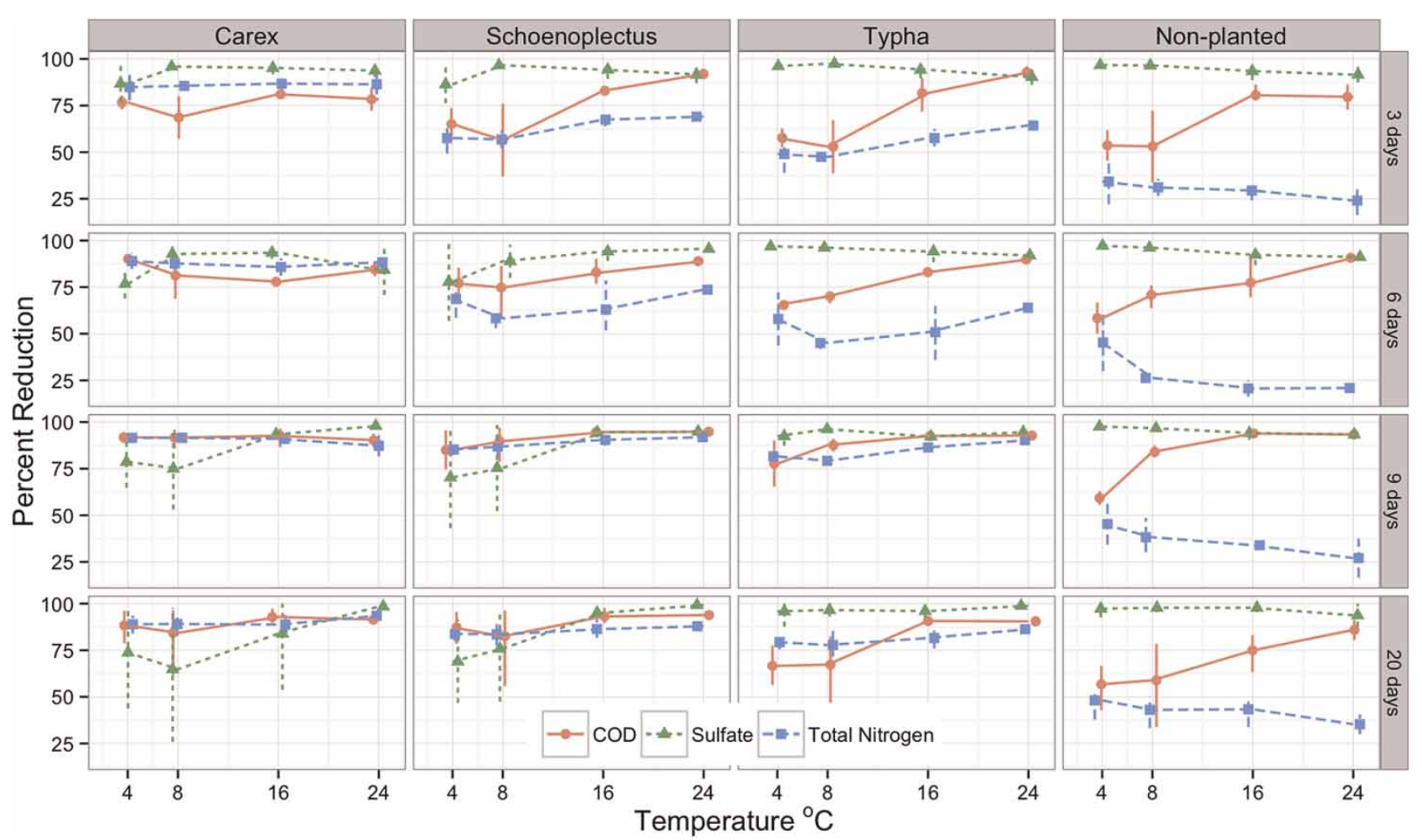

Figure 3 Percent removal of TN, COD, and sulfate at the final batch day for batch lengths of 3, 6, 9, and 20 days. Points represent mean values; vertical bars represent maximum and minimum values. 
To address the effects of loading rate on COD, sulfate and TN removal, values for the final day of each batch (i.e., at day 3, 6, 9 and 20 for equivalent batch lengths) are compared in Figure 3. Batch length is inversely related to loading rate. For example, a 3-day batch length has two times the loading rate of a 6-day batch and three times the loading rate of a 9-day batch for any given parameter; thus the data represent nearly a sevenfold variation in loading rate.

In general terms, Figure 3 shows that species selection appears to have a greater influence on treatment efficacy than temperature or loading rate, but interactions are apparent. For example, Carex and Schoenoplectus had higher COD and TN removal (TN global average removal $=88$ and $76 \%$, respectively) than unplanted systems (global average $=34 \%$ ), regardless of loading rate, while Typha (global average $=69 \%$ ) was intermediate but more similar to planted than unplanted systems. Within planted treatments, there was a general decrease in COD and TN removal and an increase in sulfate removal with increasing loading rate, but differences between loading rates were typically smaller than differences between plant species and between planted and unplanted systems. Typha and Schoenoplectus displayed the greatest variation in $\mathrm{TN}$ removal across loading rates; for example, temperature-averaged removal decreased by approximately 20 percentage points between the 9-day and 3-day batch lengths. Equivalent changes between the 9-day and 3-day batches were only 3 percentage points in Carex and 10 percentage points in unplanted systems.

Temperature effects on all parameters were fairly consistent across loading rates. Within species, parameters that showed poorer removal with increasing temperature tended to do so at all loading rates, as did parameters demonstrating better performance with increasing temperature. Sulfate removal in Carex and Schoenoplectus columns was an exception; for those species, sulfate removal diminished strongly at colder temperatures when loading rates were low (longer batch lengths) but only weakly or not at all when loading rates were high. This suggests that the increased root zone aeration observed at lower loading rates can be overwhelmed by high organic loading rates. This trend was also observed by Stein et al. (2007).

\section{CONCLUSIONS}

General trends in the observed changes in concentrations of COD, sulfate and $\mathrm{TN}$ (estimated statistically from $\mathrm{NH}_{4}^{+}$ measurements) suggest that variation in aeration of the rhizosphere is the driving mechanism for variation in COD and TN removal. Plant species selection, temperature, and loading rate influenced removal efficacy. Previously reported negative correlations between measured ORP and sulfate removal and positive correlations between ORP and COD removal indicated that variation in COD removal is influenced by changes in aerobic versus anaerobic heterotrophic microbial activity. Variation in rhizosphere aeration also appears to produce measurable differences in TN removal, presumably by influencing the activity of autotrophic nitrifiers. Plant species selection appears to have the greatest influence on rhizosphere aeration, which follows a pattern of $C$. utriculata $>S$. acutus $>$ T. latifolia $>$ unplanted systems. Greater root zone aeration is expressed in cold winter conditions, especially for C. utriculata and S. acutus. A sevenfold variation in loading rate had a relatively smaller effect on the removal of COD and TN. Higher loading rates appeared to limit the effects of increased root zone aeration by Carex and Schoenoplectus (as indicated by sulfate concentrations and ORP), but these species greatly improved TN removal, even at the highest loading rate.

\section{ACKNOWLEDGEMENTS}

Previous experiments were funded in part by USDA-NRI grants 96-35102-3837 and 2004-35102-14832. The current work is funded by National Science Foundation (NSF) grant 1034434.

\section{$\overline{\text { REFERENCES }}$}

Allen, W. C., Hook, P. B., Biederman, J. A. \& Stein, O. R. 2002 Temperature and wetland plant species effects on wastewater treatment and root zone oxidation. Journal of Environmental Quality 31, 1010-1016.

Behrends, L. L., Houlke, L., Bailey, E., Jansen, P. \& Smith, S. $200 I$ Reciprocating constructed wetlands for treating municipal and agricultural wastewater. Water Science and Technology 44 (11-12), 399-405.

Bertin, C., Yang, X. H. \& Weston, L. A. 2003 The role of root exudates and allelochemicals in the rhizosphere. Plant and Soil 256 (1), 67-83.

Bezbaruah, A. N. \& Zhang, T. C. 2004 pH, redox, and oxygen microprofiles in rhizosphere of bulrush (Scirpus validus) in a constructed wetland treating municipal wastewater. Biotechnology and Bioengineering 88 (1), 60-70.

Bezbaruah, A. N. \& Zhang, T. C. 2005 Quantification of oxygen release by bulrush (Scirpus validus) roots in a constructed treatment wetland. Biotechnology and Bioengineering 89 (3), 308-318.

Borin, M. \& Salvato, M. 2012 Effects of five marcophytes on nitrogen remediation and mass balance in wetland mesocosms? Ecological Engineering 46, 34-42. 
Brisson, J. \& Chazarenc, F. 2009 Maximizing pollutant removal in constructed wetlands: should we pay more attention to macrophyte species selection? Science of the Total Environment 407, 3923-3930.

Brix, H. \& Arias, C. A. 2005 The use of vertical flow constructed wetlands for on-site treatment of domestic wastewater: new Danish guidelines. Ecological Engineering 25 (5), 491-500.

Cardon, Z. G. (ed.) 2007 The Rhizosphere: An Ecological Perspective. Elsevier Academic Press, San Diego.

Dong, Z. \& Sun, T. 2007 A potential new process for improving nitrogen removal in constructed wetlands-Promoting coexistence of partial-nitrification and ANAMMOX. Ecological Engineering 31 (2), 69-78.

Dong, C., Zhu, W., Gao, M., Zhao, L. F., Huang, J. Y. \& Zhao, Y. Q. 20II Diurnal fluctuations in oxygen release from roots of Acorus calamus Linn in a modeled constructed wetland. Journal of Environmental Science and Health. Part A 46 (3), 224-229.

Erler, D. V. 2008 The contribution of anammox and denitrification to sediment $\mathrm{N}_{2}$ production in a surface flow constructed wetland. Environmental Science and Technology 42, 9144-9150.

Faulwetter, J. L., Gagnon, V., Sundberg, C., Chazarenc, F., Burr, M. D., Brisson, J., Camper, A. K. \& Stein, O. R. 2009 Microbial processes influencing performance of treatment wetlands: A review. Ecological Engineering 35 (6), 987-1004.

Faulwetter, J. L., Burr, M. D., Parker, A. E., Stein, O. R. \& Camper, A. K. 2012 Influence of season and plant species on the abundance and diversity of sulfate reducing bacteria and ammonia oxidizing bacteria in constructed wetland microcosms. Environmental Microbiology 65 (1), 111-127.

Huett, D. O., Morris, S. G., Smith, G. \& Hunt, N. 2005 Nitrogen and phosphorus removal from plant nursery runoff in vegetated and unvegetated subsurface flow wetlands. Water Research 39, 3259-3272.

Kadlec, R. H. \& Wallace, S. D. 2009 Treatment Wetlands. CRC Press, Boca Raton, FL

Langergraber, G., Leroch, K., Pressl, A., Sleytr, K., Rohrhofer, R. \& Haberl, R. 2009 High-rate nitrogen removal in a two-stage subsurface vertical flow constructed wetland. Desalination 246 (1-3), 55-68.

Langergraber, G., Pressl, A., Klaus, L., Rohrhofer, R. \& Haberl, R. 20Io Comparison of single-stage and a two-stage vertical flow constructed wetland systems for different load scenarios. Water Science and Technology 61 (5), 1341-1348.

Laskov, C., Horn, O. \& Hupfer, M. 2006 Environmental factors regulating the radial oxygen loss from roots of Myriophyllum spicatum and Potamogeton crispus. Aquatic Botany 84 (4), 333-340

Mainiero, R. \& Kazda, M. 2005 Effects of Carex rostrata on soil oxygen in relation to soil moisture. Plant and Soil 270 (1), 311-320.
McBride, G. B. \& Tanner, C. C. 2000 Modelling biofilm nitrogen transformations in constructed wetland mesocosms with fluctuating water levels. Ecological Engineering 14 (1-2), 93-106.

Paredes, D., Kuschk, P., Mbwette, T. S. A., Stange, F., Muller, R. A. \& Koser, H. 2007a New aspects of microbial nitrogen transformations in the context of wastewater treatment a review. Engineering in Life Sciences 7 (1), 13-25.

Paredes, D., Kuschk, P., Stange, F., Muller, R. A. \& Koser, H. 2007b Model experiments on improving nitrogen removal in laboratory scale subsurface constructed wetlands by enhancing the anaerobic ammonia oxidation. Water Science and Technology 56 (3), 145.

Pinheiro, J., Bates, D., DebRoy, S., Sarkar, D. \& the R Development Core Team 2012 nlme: Linear and Nonlinear Mixed Effects Models. R package version 3.1-106.

R Core Team 2012 R: A Language and Environment for Statistical Computing. R Foundation for Statistical Computing, Vienna, Austria.

Riley, K. A., Stein, O. R. \& Hook, P. B. 2005 Ammonium removal in constructed wetland microcosms as influenced by season and organic carbon load. Journal of Environmental Science and Health, Part A 40 (6), 1109-1121.

Salvato, M. \& Borin, M. 2oIo Effect of different marcophytes in abating nitrogen from a synthetic wastewater. Ecological Engineering 36, 1222-1231.

Schultz, R. L., Stein, O. R. \& Hook, P. B. 2008 Temperature, plant species and residence time interactions in treatment wetlands. In: 11th International Conference on Wetland Systems for Water Pollution Control. Indore, India. pp. 161-167.

Stein, O. R., Borden-Stewart, D. J., Hook, P. B. \& Jones, W. L. 2007 Seasonal influence on sulfate reduction and zinc sequestration in subsurface treatment wetlands. Water Research 41 (15), 3440-3448.

Stein, O. R. \& Hook, P. B. 2005 Temperature, plants, and oxygen: how does season affect constructed Wetland performance? Journal of Environmental Science and Health, Part A 40 (6), 1331-1342.

Taylor, C. R., Hook, P. B., Stein, O. R. \& Zabinski, C. A. 20II Seasonal effects of 19 plant species on COD removal in subsurface treatment wetland microcosms. Ecological Engineering 37 (5), 703-710.

Vymazal, J. 2005 Horizontal sub-surface flow and hybrid constructed wetlands systems for wastewater treatment. Ecological Engineering 25 (5), 478-490.

Vymazal, J. 2007 Removal of nutrients in various types of constructed wetlands. The Science of the Total Environment 380 (1-3), 48-65.

Wallace, S. \& Austin, D. 2008 Emerging models for nitrogen removal in treatment wetlands. Journal of Environmental Health 71 (4), 10-16. 